Before concluding this paper, I beg to in the region of the heart, shooting to the add, that the only cases of croup which have terminated favourably under my treatment, were cured by frequent and large doses of the protochloride of mercury. For the suggestion of this plan, I am altogether indebted to my exccllent friend and former teacher Dr. Hamilton, A few weeks ago, Miss Jane Crow, daughter of F. J. Crow, Esq., of Deptforl Hill, near this town, recovered by the agrency of this admirable medicine. I may remark, by-the-by, that another infant of the same family, aged three years, had recently recovered from hydrocephalus by the frequent nse of large doses of the protochloride, thongh I was not in attendance until the third stage of the disease. She was blind for a fortnight. In a few days she took 120 grains of this medicine. I remain, most respectfully yours,

Sunderland, March 21, 1836.

W. REID ClANXY.

\section{DIAGNOSIS OF DISEASE OF THE HEART.}

\section{CASE OF PLETHORIC INFLAMMATION OF THE HEART,}

\section{Presumed to be Pericarditis,}

FOLLOWED BY PIETHORIC ENLARGEMENT OF THE HEART, AND HYפTERICAL MA XIA, OF THREE YEARS' STANDING; TREATED SUCCESSFULLY.

By John Fosmone, M.D., Physician to the Ross Dispzensary.

Is my last paper on nervous, plethoric, and symptomatic palpitations (LANCET, vol. $1,1835-36$, page 620), 1 explained, in a general manner, my ideas of the influence which the nervous and circulating systems exert over both organic and functional dis. eases of the heart, and of the practical necessity of viewing these diseases through the medium of morbid action. I shall now give a case of heart disease of the first mag. nitude, and point ont how those views were applied to its discrimination and treatment, which last has been eminently successful, after three years' management, by several esteemed physicians and surgeons to public institutions, and the abandonment of the case by them as incurable.

\section{Case.-The Primary or Acute Disease, in 1831 .}

On the 27 th of May, 1832, Ann Howls, ætat. 16 and above, a tall, riddy.faced, country girl from Herefordshire, came to me at Cheltenham with a tremulous ap. pearance of the hands and body, an expression of anxiety in the countenance, and distressed respiration. She complained of pain angle of the left scapula, and of great pain catching her under the ribs in the same region during inspiration. The pulse was not much, but the heart's action was, very visibly, quickened. She attributed her com. plaint to going from Walford to Ross by night, and "seeing something," which turned out to be the heals of two or three asses looking over a hedge, and biting off the tops. These apparitions frightened her to such a degree, that she roared out lustily for help, and found a violent sensation catch her in the region of the heart. 1 ordered ber to be bled, and prescribed a combination of squill, colchicum, and tartar emetic. On the 28th of May she left a message that she was worse. On the 29th of May she sent for me, and, on going to her, $I$ found that the pain in the left chest was increased; the shock of the heart's impulse was so violent as to be visible. She had fainted in going up-stairs, and at last could not ascend at all, and had had, in fact, several attacks of syncope and increased palpitation. She felt pains in the claricular and lower scapular regions, which were rendered worse by inspiration; she could lie only on her back, and felt instantaneous sickness, and a load, when she turned on her left side; the heat of chest on that side was very great, and the noise to the ear like that of a saw-mill, and the respiration like a loud rushing sound. On the right side the respiration was natural; the symptomatic fever was very strong; the pulse hard, round, and quick, on the right side, and smaller and more compressible on the left; the expec. toration was offensive; the tongue was coated with brown fur; there were herpetic ermutions on the lips. She was bled inmediately ad deliquium, and the fainting was followed by convulsive motions of the body, of an hysterical character, and by spasmodic pains in the region of the circulating and respiratory organs (which were mixed up with the disease throughout), with a bluish tinge of countenance. A blister of the largest size was put on, and tartar emetic was given, after Laennec's system, in doses of from twelve to twenty-four grains.

At three o'clock p.m., she complained that the pain, which caught her low in the left ribs, was increased, and that she felt a load in the chest, like a great weight. She was then cupped by Mr. Kitsell, druggist, at Cheltenharn. In the course of the evening nausea came on, and then a violent purging and vomiting, chiefly of bile, from the tartar emetic.

This girl was bled two or three times afterwards, and cupped a second time, for violent returns of the paroxysms of pain, palpitation, and painful respiration, with decided mitigation of the symptons. The blood was buffed, and contracted at the edges. The pain did not cease entirely un- 
til after the last bleeding; previously to that step, it was less at one time and worse at another, and came on in paroxysms. The symptoms of these paroxysms were, syncope, pain at the scrobiculus cordis and lower bone of the sternum, and upwards towards the left axilla, with a sensation like a flame of fire passing from the heart into the neck. Indeed, the symptoms presented a dubious character, as if partly infammatory and partly spasmodic, and much hysteria was mingled throughout. The blister was kept opeu, and antimonial ointment applied. The tartar-emetic solution had been continued, but produced great sickness, purging, and irritability of stomach, bordering on gastritis; after the first two or three days I, therefore, reduced the quantity, and added hyoscyamus, \&c. Two-grain doses of opium, with a scruple of calomel, did not produce sleep.

She began, as $I$ have stated, to recover rapidly from the active symptoms after the last bleeding, but, upon attempting to resume her occupation of cook to Mr. Rawling's family, upholsterer at Cheltenham, and to expose herself to the fire, against which 1 warned her, the pain returned, in a mild form, with futtering in the chest, like that of a bird (which was relieved by leaning forwards), combined with swelling of the legs, and some hysteric symptoms. I jrescribed gamboge, elaterium, and calomel, for her, and sent her home to Ross, for the sake of native air and repose, with a re. corrmendation to Dr. Thomas Evans, then of the Ross Dispensary, and now physician to the Gloncester Infirmary.

The Consecutive Disease of the Heart. Plethoric Hypertrophy, with Dilatation and Fysteria, in 1835.

But the most curious and important part of this case is now to follow :-

Having left me at Cheltenham, she went into the Ross Dispensary, under Dr. Thomas Evans, as "No. 1676,17 ætat.," recommended hy R. Blakemore, Esq., on the $18 \mathrm{th}$ of June, 1832, and was discharged on the 16 th of Angust, as a case of "Pericarditis" "Relieved," by cupping, hlistering, or bleeling every week, and a breal-pudding diet. She then entered the Hereford Infirmary for three months, under Dr. Walkron, who leeched and blistered her all round the heart. She got worse while she was there, but something better after she came out. She then resorted to Dr. T. Evans again, who went over the same ground with her as before. She was admitted into the Ross Dispensary, as No. 1768 , Nov. 23, recommended by the Rev. J. Thiskell, and entereal as a case of "Hypertrophy of Heart." Her fourth doctor was $\mathrm{Mr}$. Goodrich, surgeon of the 35th Royal Sussex, at Stroud, who gave her asafutida. Her fifth was old Mr. Minster, at Cheltenham, for abont a fort- night, who prescribed the same. She then went a third time under Dr. T. Evans, into the Gloncester Infirmary, who prescribed the fetids, applied tartar-emetic ointment. and put her under a course of mercury, which never affected her mouth. "A cupping of the loins by the house-surgeon, for a pain there, did her heart and head more good than anything else." Her sixth and seventh medicals were Mr. John Wilton and son, who bled her cvory day for a week, leeched her behind the ears. and gave her medicines for nine or twelve montbs. The eighth and last, except myself, was Dr. Shute, a gentleman of talent and even originality, whose merit has been as much under valued and unrewarded as the pretensions of some deep adepts in "that admirable compound of folly and knavery called the world," to use Sir Walter Scott's language, have been undeservedly overrated and confiled in for supposed high superior talent. She remained under Dr. S., at the Lunatic Asylum, Gloucester, for three months; she was there purged and blistered, sometimes three times a week, at the back of the neck. Mr. Hitch, the house-surgeon to that institution, who is a gentleman of scientific habits, kept her head constantly wetted with vinegar and water, and the room in which she was, sprinkled. She was sometimes vociferous and obstreperous, for which she says she was soused by the nurses in a cold-bath. They are not permitted to strike the refractory, and the plurging bath appears to be an excellent substitute for that mode of coercion. The head is every thing at thase institutiors, and the orrer of the day was to get down the excitement of the brain, and never to mind the hearc. The ironing and washing, the leaning over the soap-suds, and the noise of the wangle, with which she had to do, disturbed the heart; but she left the asylum with a heal restored to tolerable tranquillity, and tree from a so-frequent recurrence of the fits.

Having gone this round for three years, and more, from one public institurion to another, and from one rredical "star" to another, she had reconrse to me again at Ross on the 20th of July, 18.35. I put her into the Dispensary as a case of hypertrophy, and perhaps dilitation.

She stated that. from the time she left Cheltenham in 1832 to that day, July 20, 1835 , she had continued subject to riolent palpitation, and spasmodic and hysteric seizures. The thumping of the heart was so violent as to raise the bed-clothes, but rot so violent when she lay with the head high as when low. She was also affected with a great beating at the top and back part of the head, generally before the coming on of the hysteria. The hysteric paroxysms were so desperato that she could with difficulty be restrained by severai jersons. She would sometimes bolt out of the 
house and run helter-skelter down rugged lanes and over stceps, at the risk of dashing olt her brains. These fits were preceded by the most forcible motion of the heart, giddiness, and symytoms of rushing of blond upon the heal, They at last devrived hor of her reason, and before she went inso confirement, she hat! several attacks daily, but they now came on at intervals of seycral days. I found that she lad never been regular. The first appenrance was at 16 atat.; since that time she had gone over somotimes two, sometimes four, and sometimes seren months; for the linst twelve months she had been unwell twice, but for two diays only each time.

The pulsation of the heart, in the left chest, was b.rely audible in the axilla; it was not andible under the clavicle; it was more andihle from the axilia to the stomach In tho right chest, it was slightly audible under the clavicle, breast, and right side of epigastrium. No audible pulsation at the posterior walls of the chest, on one sile or the other. According to her own feelings, the pulsation is greatest at the epigastrium, under the lett breast, and occasionally at the first bone of the sternum and throat, esspecially in going up and down hill. The impulse, which is very great both at the epigastrium and between the 5 th and $7 \mathrm{th}$ ribs, is sometimes most at one point, sometimes at the other. It is most fiequenty in greatest force at the last point; but attended with the greatest pain and heaviness at the pit of the stomach. The impulse has been such as to shake the bed-furniture!! It repels the stethoscope, and leaves no doubt of the always inordinate, and somerimes excessive, action of the right and left ventricles. The bruit is not greater than natural in either cavity, to my ear, hut she says it is sometimes audible to herself and others, particularly at getting out of bed, and, when it occurs, she spits blood immediately. The space between the contractions of the auricles and rentricles, is certainly more strongly marked than naturally. As to the rhythm, the left ventricle beats stronger and oftener than the pulse. I find neither bellows, file, nov cat murmur. She is not kept awake at night by the most violent palpitation. (July 20)

$I$ determived on a plan of treatment more comprehensive, more varied, and more decisive, than the previous methods of the "Nobs" who had gone before me.

July 20. Commenced with a combination of squill, aloes, sota, and sulphate of zinc, but as pills make her vomit, she was obliged to gire them up, and took, instead, threedrop doses of hydrocyenic acil, combined with scruple doses of tinct. lyttre, and tivo simple doses of wine of ipecacuanha. En. joined to lie on her hack, and eat no more food than was suficient to preserve life, and to llink nothing but slops; a commandment scarcely called for, as the girl ate next to nothing.

29. Palpitation the same; three tremendous fits, but at longer intervals than before. One scruple doses of chenopodium ollidum, and two scruple doses of tinct. aloes, to be added to the hydrocyanic mixture, to act npon the utcrus, as a certinin period was approaching. As the monthly warning yassed over without any appearance, I left both out on the 3ril of August, and substitutel half-grain doses of tartar emetic. To be cupped every week. Ilead better, but heart the same.

Aug. 9. Heart acted npon by the hydrocyanic mixture; palpitation so much diminished, that she can hardly hear the heart beat. Ordered to go on until she does not know that she has a heart. Has lain on her back, as she was ordered, the greatest part of erery lay, and would have laid the whole riay, if the people about her would have let her. No hysteric paroxysn for a fortnight; then a more violent fit than for the last gix months. Leeches and blisters to the upper part of the thighs; hot pediluvia to bring down the catamenia if possible.

12. Palpitation, pulsation of carotids, flut tering at the sternum still violent in going up and down hill. Giddy from not being cupped as usual once a week; therefore to have a seton. Catamenia not yet repro. duced by the remedies : on that account turpentine enemata to be thrown up twice a day.

14. The catamenia has come on without the turpentine injections. Palpitation increased by the usual excitement of this condition, and going up and lown the Dockpitch: therefore one grain more of tartar enetic to the mixture.

16. Hysterical globus; pain of epigastrium and left side under the ribs; and pain and extreme tenderness of the whole abdomen, increased by pressure, which prevents her lying in the horizontal position; breath short, from the pain of the stomach; pain under the scapula and along the left arm; mind wandering. Twenty leeches to the seats of pain. Valerian and nitrous ether to be taken occasionally.

22. Pain of epigastriam the same, but pain of left side greatly relieved by the leeches; globus, palpitations, loss of mind twice a day, formerly nine times a day. Turpentine injections used, but have no effect except in increasing the secretion of the kidreys.

24. Better in all respects, but Marianne Adlis, who slept with her, says she could distinctly hear the heart pulsate, and that the heart beat three times for the once of the pulse at the wrist; head better; epigastric pain not so violent; now for the first time an eager appetite for food. But, on this very evening, she had a two-hours' fit, probably from going over the day without 
ker regular cupping. Eight leeches and blister to the upper part of the thighs.

26. Cupped to zxviii.

28. Heart much more regular ; epigastric pain less, but pain of left side violent when lifting or heaving. Does not eat so much as two biscuits a day; can eat a little fish, but no meat. Liniment of mercurial ointment, Iodine, and croton oil, to be rubbed upon the chest; dose of tartar emetic to be increased, and the hydrocyanic acid to be augmented to four drops twice a day.

31. Threatenings of a fit. Cupped therefore to $3 x i i$. The leart beats less, but she hears a sound like a file, when she lies on her back with her head low, or when she is startled, or exerts herself more than usual, particularly in going up hill.

Sept. 2. Her head has been so quiet that she has had no beating in it except at getting $" \mathrm{p}$ in the morning; every pain better; thinks "the seton has done her a wonderful deal of good."

4. Palpitation again for half an hour at a time; violent pulsation at the back of the head, with a feel as if the occiput were opening and shutting; increased pain of epigastrium, and pain in the right hypogastrium; disposition to hysteria, and much mobility exhibited, by restlessness, fidgetting from place to place and thing to thing. To use the shower-bath, which relieved her.

5. Two violent attacks of palpitation and beating in the head at rising and before noon. Shower-bath again. These attasks probably owing to the approaching period.

7. Light-hearledness, but heart very quiet; afraid that a child with chin-cough has infected her. Cupped to $¥ \mathrm{xii}$; four showerbaths a day.

9. Her month gone round ; crural leech ing and blistering; hydriodate of potass and turpentine given without the desired effect. Again affested with pain cf lett shoulder and arm.

11. Some catamenial appearances, but with a disturbed state of biain, globus, and, as often before, a disposition to suicide; pain under left arm; nueasy respiration and fle noise continue. These symptoms have followed a violent cold, and accompany chilled legs and skin. She still thinks the heart is a great deal improved, and that I shall cure her.

14. Beating at the rack of the head, and the feeling as if the head was being burst open at that part, by some force from within. Bled to $5 x i v$ by $\mathrm{Mr}$. Gwyme.

15. A two-hour's fir, but muscular convulsions not so violent as folmerly; lies more lifeless than usual after it; all the morbid sensibility of the skin, and particularly about the seton, for which she was always wanting me to pull it out, took leave after this fit. She spat blood before the last and other fits. Has beating under left scapula and along the left arm.
20. Violent action of the heart, with the spitting of a good deal of blood, and beating of the back of the head. Ten lecches behind the ears. Symptoms ceased at middle day.

30. Two fits in one week, but formerly had nine per day for nine weeks; found when they were coning on, by the globus, and icy coldness of feet, and extreme heat of head. Put her head under a pump, and got it pumped upon to lessen this heat, which has always been very great. 'The heart palpitates during these fits, but the impulse and other important symptoms of enlargement have long since vanished, and the seton has been withdrawn. The last fit was caused by a foolish body runuing in with a cockand-bull story about a sudden death. She has not been cupped or leeched very lately, but has used the shower-bath, and taken squill floated on compound elec. of aloes.

Oct. 12. No fresh fit, but full of hysteric feeling; great palpitation without impulse; excessive beating of the innominata, evi. dently connected with, if not caused by, the bysteria, with noise in the head, as if some one were blowing into the skull and in to the right ear, with discharge from the right ear, wherein she has been deaf since her head was first affected. She ought to have been regular on the 11 th, but has not been so, and has been affected for some days with pain in the right ovarian region, swclling in both ovarian regions, moming weakness, and odematous legs, like the first signs of interrupted catamenia fiom preg. nancy, but not uncommor in hysterical subjects; head light and wandering. Leeches (xii) and blister to the thighs; large doses of hydriodate of potass, with the tr. cantha. rides, to no purpose.

20. Head much affected, and mind so irritabls, that slie can only relieve herself by stamping, rociferating, and cursing lustily at every ore who comes near her. In this state she hurried, of her uwn accord, up to town (the carotids pulsating so violently as to be remarked by people in the street), and got bled to zaxi.

27. Lost 3 xxii more blood, the blood spurting up to the ceiling, and scarcely to be stopped. To take 60 drops of tr. digitalis in the day.

28. On came the palpitations, but without impulse, for the disease, "when it does not attack one part, makes at the other, the heat or the heart;" extremities too cold, and all the rest of the body too hot; monning sickness; pain of right hypogastrium and swelling of legs continue. Has been without a fit longer than usual, which she ascribes to a bleeting in the foot.

Nuv. 16. More than a fortnight without biecding. Has had two fits at the Dockpitch, for which some people first swilled. her with cold water, and then thinking it " would give her her death with cold," 
choked down some rum, which cansed a violent rush of blood to the head, and raving madness. After three days' insanity, and driving about the country and bouncing about the honse, I prostrated her with tartar emetic in strong doses. The moment she attenuted to rise in the bed, it made her so wretchedly sick, that she was glad to lay down her head and be at peace. Under the action of this agent the catamenia came on, and the merital excitement began to lessen greatly. I now kept on plying her with $5 \mathrm{grs}$. of hydriodate of potass, 15 drops of tinct. digitalis, the same of tinct. hyoscyamus, and $19 \mathrm{gr}$. of tartar emetic, three or four times a day. Tuis invaluable combination has always had the effect of "killing her," as she tertns it, "for half an hour," by suspending the action of the heart, pulse, and respiratory organs, nay, almost suspending atimation.

Nov. 27 to Jan. 25 . The violent palpitation, with spitting of blood, and the file noise in going up and down stairs, which had all returned, were removed by this remedy. On the 27 th of November she appeared convalescent, for there had been no palpitation, no determination to the head, no fit, and no signs of fulness. From that date to the present time (January), she has continued to improve, and has become perfectly regular, - a circumstance which she had never known in her life. If she feels her head or heart menaced after chills, or nervous, or mental shocks, she has recourse to half doses of the last medicine, and wards off all mischief. She now thinks of going to service in the $\operatorname{sprin}_{\varepsilon}$.

\section{Remarks.}

I shall pass over the acute attack, whether congestion of the internal menbrane and substance of the heart, or inflammation of that membrane, or pericarditis, until I come to Mr. Gwynne's case, which was similar.

Before she left Cheltenham, I cautioned her mistress that if she returned to cooking, and exposed herself to the stimulus of heat, she would have a renewal of discase about the heart, and it so turned out. She departed with syroptoms, in her own words, "something like a bird fluttering with both wings on the chest, particularly at the pit of the stomach more than at the side of the chest," with " inability to lie on the left side for a monent for the continued cough." These signs, which, so far as their equivocal nature admitted, both $I$ and Dr. Evans interpreted into mild and subdued pericarditis, soon made a transition into the established form of enlargement of the heart by thick. ening, if not dilatation. Everywhere that the nuscles of organic life are in contact with an infamed nembrane, whother mucous or serous, they have a remarkable tendency to become the seat of a more active nutrition,-that is, to hypertrophize. But increased determination of blood (to which and plethora $I$ ascribed this disease), can of itself produce only congestion of the heart. It can never cause hypertrophy, unless when aided by a corresponding increase of the assimilating powers of the part, and an increased exercise of the functions of the affected organ. (M.Andral.)

Speaking of these transitions, Professor Andral observes, that the practitioner ought to investigate the least symptom after apparent convalescence, and never cease from combatring the enemy, so long as he offers the least sign of his presence. If there be merely a slight pain in the heart's region, with some fever, and a respiration not free, he should not stop short of the last requisite and decisive bleeding. An arrest, ar amendment, or a suspension of the disease, may have been effected, but the inflammation may return, or the discase may pass into a chronic state. Howls might, or might not, have wanted this final security. It is my opinion that excess of nutrition and sanguification were the predisposing causes of heart disease, both in Howls and Mr. Gwynne.

Irregularity and deficiency of the cata menia is one of the principal causes of plethora in women. (M. Martinet.) The want of a proper development of this secretion, and the consequent retention in the system of an excess of the circulating mass, from sixteen years of age, to the period of her recovery, greatly conduced to, if it was not the one great cause of, redundancy and morbid determination. Professor Macartney remarks, that suppressed secretion of the uterine surface will produce the most violent action of the heart. Nothing could show more strongly the importance of the periodical uterine function, and the necessity of re-establishing that function, if possible, than the exasperated excitement of the heart, the disturbance of the brain, and the recurrence of the fits on or before the catamenial effort. She noticed this circum. stance herself, but laid some of the blame upon the moon.

Anotlıer cause of plethora was a change from the free out of -door habits of the country to those of a being "in populous cities pent." Howls goes out of Herefordshire to be impounded in the kitchen and kitchen-area of a Cheltenham dwelling-house. Mr. Gwynre was sent early in life from the range of a homestead to that of a druggist's counter at Newport. The symptoms of irritable heart quickly followed this change, and he was cured by a temporary return to home and agricultural occupations. In 1835-6 he is confined to Mr. Bellamy's shop at Ross, and he has three pericarlites and one pleurisy within less than a year, and can only con. ralesce with the help of enlargement, change of air, and open exercise. There are few of 
our "vulgar country constitutions," like/become redundant upon a diet of bacon. Lydia Melford's, in Humphrey Clinker, rinds and cheese-parings, and so are subject "reared among woods and mountains," that to a condition, which is one of the greatest can bear the rus ad urben change, and the misfortunes of life.

consequent change of habits, without more Such wcre the circumstances that showed or less injurious results. Dr. Parry's pecu- the disposition to excess of sanguification; liar doctrine of nervous diseases spring- and $I$ consider that the excessive quantity, ing from irregular circulation, caused by and rich, fbrinous, and stimulating quality, " the defect of due exertion of the voluntary of the blood, by producing accumalation in muscles" and morbid stimuli,--and Andral's the cavities and over-stimulation of the maxim that "too much food, while the heart, was the exciting, but not the sole body loses too little by exercise, gives a dis- exciting canse, of the disease. I revert to position to inflammatory diseases," apply with felicity to certain morbid actions of that great involuntary muscle, the heart.

Howls's kinsfolk, seeing that she atelittle more than two biscuits a day, and yet required perpetual bloodletting, were always bothering me with the question, "How she could make so much blood and cat next to nothing?" "What is the use of your chaffing," was my answer, "when she is plainly one of those, who would starre, like a Scotchman, upon oaten bannocks and porridge, or, like a Muscovite, upon the bark of a tree, and yet carry a 'purple regal stream ' in her veins, full to overflowing." During the three years and $a$ half that she went from Cheltenham to the Ross Dispensary, from the Hereford Infirmary to Stroud, from Stroud to Cheltenham, from Cheltenham to the Gloucester Infirmary, and to the Lunatic Asylum in that city, and thence to me, she lived a continual life of bloodletting, cupping, and leeching, day by day, or week by week, and "she was never so happy," she says, "as when she was gaing to be bled." Most times, when she had let the customary week-day for blecding go over, her carotids commenced beating, her temples throbbing, and "the back of her head felt ready to split;" as if the blood, interrupted in descending from the lateral simuses, distended the skull; then out she would sally, in terror of an hysteric paroxysm, without any instructions, and have blood removed. Hydrocyanic acid, digitalis, ipecacuanha, and neutral salts, and all kinds of sickening and depressing agents, in strong doses, did not arail to prevent sanguification, and the necessity of depletion. A glass of wine she conld bear, but any quantity of spirit and water drove her mad. It injected and excited the vessels of the brain, and overwhelmed her mind before the cri. tical amelioration of the end of November. Dr. Macintosh gives an extreme case of hypertrophy, which was treated in a man. ner worthy of his talents. The man, notwithstanding bleeding and ontimony, began to increase in flesh and strength as soon as the antimony was omitted, after which " he had perseverance cnough to live for a considerable time on two biscuits a day." Thus, while there are some who look as if they were made before blood was in fashion, there are others who will what 1 said, in the preceding paper on palpitations, on the mixed nature of the morbid action. I see an acute attack presenting the most violent symptoms of pericarditis. During that attack she has spasmodic seizures, and disturbance of the brain of an hystcrical character, combined with the effects of increased vascular action, and ever and anon re-excited to exasperate the palpitation and more fixed symptoms of in. flammation. The acute attack is subdued, and she is subject for three years afterwards to palpitation, with impulse, and the charac. ters of hypertrophy, if not dilatation, which coincides with a disposition to make blood in excess, and, consequently, to become subject to engorgement of the heart's cavities. But the acute attack, like two of Dr. Parry's cases, the one pericarditis, the other another aftection of the heart, was brought on by terror, and the consecutive disease of the heart was always aggravated by every un. happy circumstance that could operate on the mind, and little else had she but such circumstances to encounter. I look not to the mere material change from a thinner heart to a thicker, from smaller cavities to larger, to a doctine of mechanical obstacles, nor exclusively to an engorgement of blood, but I hold fast by the precept of Professor Macartney, that in studying the dis. eases of the heart, we should regard not " morbid structure alone, but morbid action in connection with morbid structure."(Notes of Pathological Lecture.) I see in this case the plethoric condition of the heart accompanying " that condition of constitution which is usually called nervous, in which the heart is peculiarly disposed to be aflected by the whole train of mental emo. tions," in which " the effect of blood on the action of the heart is not always proportioned to the absolute quantity, but often to the previous circumstances of the heart itself," and the co-existence of what "is called the nervous constitution." It is also well remarked by M. Andral, that not only will a plethoric state produce excess of action and palpitations, and, by prolonging the excess of the heart's action, hypertrophy, in the same manner as violent exercise will cause increased thickness of a muscle, proviled there be a disposition to increased assimilation, but that a vice of the nervous influx will produce the same effect 
with force and irregularity, in like manner as it produces the most disordered movements of the life of relation. Now I regard the plethoric state and vice of the nervous influx, not as existing separately, but in combiration, in Howls's case, and the palpitation not merely as an effect of thickening, but symptomatic both of it, and plethora and hysteria.

The redundancy of blood and excessive action of the heart in a state of hypertrophy, added to the irritable, and perhaps congested state of an irregular uterus, produced throbbing carotids and morbid determination to the head. "No fact is better ascertained than the influence which simple hypertrophy exerts in producing apoplexy and softening of the brain." (Dr. Mackintosh.) Dr. Craigie has reported cases of combined disease of the heart and brain. (Edinbargh Medical and Surgical Journal, No. 74.) Dr. Hope, whose work I have not yet had the pleasure of reading, has pointed out in how great a proportion of cases, apoplexies follow hypertrophies. Dr. Parry, indeed, had described the violent pulsation of the carotids in cases of enlarged heart, with a tendency of the thyroid gland to enlarge, and so divert the blood from the brain; and $\mathrm{Mr}$. Abernethy had observed, that in aggrandizement of the heart's substance, with aggrandizement of its action, the pulse is enlarged in its diameter, the carotids pulsate, and both are dilated, to carry off the quantity of blood forced upon them; Professor Macartney also has noticed the fact that inordinate action of the left ventricle will produce apoplexy of the right hemisphere, by forcing upon parts not meant to receive it. M. Andral remarks, with great correctness, that the consequences of an hypertrophied left ventricle, with nnaccustomed energy of contraction, are affux towards the head, from the disposition of the arteries which carry the blood thcre, puffs of heat ascending into the head, swimmings of the head, and active congestion, whenever palpitation is felt. A great degree of congestion may be announced only by headache, vertigo, and swimming; a second degree, by a complete loss of consciousness, and all the symptoms of cerebral hemorrhage; and, lastly, effusion itself and apoplexy. When these symptoms of active congestion are dissipated very promptly under the influence of copious bleeding, it becomes very evident that there existed in the brain only a momentary plenitude of the red capillaries, without hemorrhage, but, in the other case, there is a real erfusion of blood. In Howls, the increased palpitation, the spitting of blood before the fits, the pain under the left scaplila along the left arm, all which precede accumulation of blood in the heart's cavities (Dr. Parry), and then throbbing carotids, bursting distension of the lateral sinuses, and hysteric

No, 657. paroxysms, evince a connection between fulness of the heart, and active congestion in the lungs and head. Imperfect or unaccomplished uterine efforts at the catamenial period werc the forerunners of in. creased palpitation, and morbid determination to the head, and the signs of a want of balance of the circulation, arising from the blood not being directed in its natural conrse by the regular fulfilment of the uterine function. "Suppressed secretion of the uterine surface will produce the most violent action of the heart, and, if efforts are made to reproduce the secretion which fail, it will become still more interrupted" (Professor Macartney).

Dr. Parry has shown that palpitation long continued will produce determination to the head and hysteria in females, and epilepsy in men. The plethoric hysteria of Howls, which was the most formidable and rebellious symptom which I had to combat in that case, was that kind of disordered nervous action to which her constitution, like other nervous constitutions in females, was prone, and was excited principally by irregular circulation in the brain, and uterine irritability. The hysteric attacks lessened in violence, frequency, and duration, in proportion to the progressive improvement of the heart's action, and ceased altogether when palpitation and morbid determination were wholly removed, and the irregular and deficient catamenia restored. But though the fits were preceded by cold feet, and the symptoms of congestion of the heart and chest, it is equally true that tumult of heart sometimes followed, as well as preceded, the hysteria, and constituted the nervous palpitation symptomatic of hysteria, together with the palpitation of a plethoric and enlarged heart. In a case of hysteria, treated by Dr. Roe of the Westminster Hospital, we find violent action of the heart, and intense pain of precordia, forming an excellent counterfeit of heart disease. When blended with actual disease of the heart, as in Howls, it is a source of great ambiguity and difficulty in adjusting what belongs to the morbid sensibility of hysteria, and what to the organic disease.

The acute pain of the epigastrium and left side at one time, of the ovarian regions at another, with interrupted catamenia, œdema of legs, and morning sickness, and the morbid sensibility of the skin around the seton, the whole of which disappeared after the great fit and consequent amelioration of the 14th of November, were nothing more than high hysterical irritation, assuming the painful character of inflammation. Sauvages has described the hysteria stomachica, Dr. Wallace, an abdominal hysteria, which mimics periconitis, and which was once so mingled with inflammatory symptoms, in the case of a female at Cheltenham, as to induce me to carry bleeding farther than 
was necessary, though safe. Dr. Macleod has given some observations on such cases, condemnatury of bleeding, but I have found leeches afford decisive relief, as in Howls's case.

Mr. Gwynne's case, which is a similar one of the first magnitude, will give me an opportunity of commenting on many interesting individual symptoms of heart diseases, which I shall now omit.

With respect to the diagnosis, Dr.Thomas Evans told me at Ross, in August 183j, that Howls's was a case of hypertrophy, with dilatation, and $I$ have a strong impression on my mind, that, in the preceding summer, he stated the existence of valvular obstruction. The impulse at the third bone of the sternum, and, according to her own account, sometimes as high as the first bone, and, when going down hill, as high as the throat, and the impulse between the fifth and seventh ribs at the left mamma, were certainly indicative of hypertrophy. In the first three examinations I found the pulsation but little, if at all, more extended than in the healthy condition of the heart, but it was audible in the right chest, a circumstance common in phthisis and other diseases of the lungs, and originating from other causes than dilatation. On the fourth examination I discovered increased pulsation under both clavicles, and there might be "that remarkable increase of cavity which exists with increased thickening of a hollow organ." (M. Andral.) The bruit might cither indicate dilatation or moderate hypertrophy. The rhythm was not that of the last degree of hypertrophy; I discovered no signs of conuracted orifices or obstructed valves, but one day that she was sitting in a chair, and two ladies came in, she was furried by their presence, and $I$, who was sitting a couple of yards off, heard a sound proceeding from the sternum; the females, who were quite as close to her, could not hear it, such a difference does the use of the sterhoscope make to the ear. She told me that when the heart was very irritable, when she walked up hill, or when blood was crowded, through emotion, into its cavities, or, particularly wher she first awoke in the morning, and changed the lying-down to the upright posture, this noise would come on, and that it resembled a file. As the presence of impulse is no infallible sign of hypertrophy, since it occurs in nervous palpitation, so the absence of impulse is no certain criterion of the non-existence of hypertrophy; thickening of the heart and its parietes is not the only condition necessary to produce impulse, its fibres should contract with energy, which does not necessarily and regularly result from increased thickness. Hypertrophy of the ventricles, with enlarged cavities, and simple hypertrophy of the left ventricle, with great diminution of its cavity, may exist without impulse, On the other hand pericarditis, a plethoric state, or a modification of the nervous influx, may produce that force of the heart's beat, and the bruit, rhythrn, and extent, which are significant of organic lesion, when no organic disease exists. Though the extent of the beat of the heart is proportioned in most cases to the volume of the heart, and remarkably to the dilatation of its cavities; yet in a great number of cases of enormous heart, the beat has been circumscribed to the precordial region, to the bottom of the sternum, and below the left clavicle. The heart may acquire a very considerable volume, and its cavities may be very much enlarged, and nothing unusual pertain to the beats of the heart; they may be even less than in health. (M. Andral.) After weighing deliberately all these sources of fallacy, and allowing them their full weight, I concluded that hyper. trophy, and probably dilatation, existed, be. cause the stethoscopic signs had been dur. able throughout, and concurrent with other signs, - and because the epoch and mode of appearance of those signs, and of the different morbid phenomena accompanying them, were really characteristic of organic disease. The file as well as the bellows. sound coincides, in a certain number of cases, with an obstacle to the free passage of blood through the heart's cavities, but they may also exist with or without obstacle, and depend sometimes on a more considerable quantity of blood than usual surmounting the orifices of the heart. To this last cause, as the file-sound was not permanent, I ascribed that sound in Howls's case. Mr. Abernethy says that thumping of the heart against the epigastrium, to dis" charge its contents, is the principal symptom of ossification of the tricuspid valve. (MS. Notes of Lect.) Andral observes that in the healthy heart, the beats are but little sensible at the last piece of the sternum and ensifor'm cartilage, and in one case where it was sensible, without bruit or impnise, the right auricle was enormously dilated. I have dwelt minutely on the diagnosis, for in diseases of the heart, above all others, a man should be able to give a reason for the faith that is in him. We should never forget that "affections of the heart may be manirested, and the affection not exist; and, on the other hand, a very grave affection may exist, and not be revealed by aus. cultation." (M. Andral.)

\section{Treatiment.}

The practice in these cases is regular Sangradoism. "Ce marveilleux secret est renfermé dans ces deux points, dans la saignée, et dans la boisson fr'́quente. *** Qu'il ne fant que snigner et faire boire de l'eau chaude. Buvez de l'eau abondamment. * * * le cours de sang, est il trop rapide, el en arrête l'impctuosité." Tery true, and "de l'eau chaude qui n'a pas bonilli; car 
j'ai observè que l'eau, quand elle a bonilli, est plus pesante et moins commode à l'estomac!" In other words, all things cold are the rule in heart cases, because warm excite palpitation. If there are those who impeach this practice, there are, like Sangrado's rivals, who could expose his failures, but could not show their own success. More cases have been lost by the pigmy school, from sparing the bleeding and water system, than were ever killed by the abuse of it. English practice in diseases of the heart has been feeble and unsuccessful. Even Parry, who was called the Sangrado of Bath, said that palpitation of the heart with organic disease was always fatal; and Baillie observes that he has known two cases where the enlargement was stopped at a certain point, and the increased action of the heart subsided, but such a fortunate issue was very rare. I have myself seen cases treated by what are called "Nobs," which, I think, terminated in a speedy interment, from want of energy. Some of us manage matters better now. "In cases of accumulation of blood in the cavities," said Parry, "keep the habit in a state of depletion, and repress as much as possible the action of the heart and arteries." Vasalva and Albertini have reduced the plan to system, and pursued it with great energy and success in angina, hypertrophy, and aneurysm; and Pelletan has profited by bleeding and starvation in the last class of affections. Macintosh takes the same course. It was by this system that $I$ reluced an aortic ancurysm to a passive state, and restored the patient to health and labour, in the case of John Marshall, reported in The Lancet, April, 1835. I adopted the same line of practice in Howls's acute attack. The infirmary phrsicians and surgeons took it up where 1 left off, and I again, in turn, readopted it; for she "was never so happy as when she was going to be bled;" and Marshall, weakened by morbid determination, "was never so strong as after being bled." But there are objections to the practice. I wish to dispense with it, if I can find a substitute, and $I$ have some hopes that $I$ have found one.

I observed the proportion between the clot and serum, and ordered a watery diet, a la Sangrado, that less fibrine might be formed, and the inflammatory disposition, promoted by too much food, while the body loses too little by exercise, be prevented.

1 considered Dr. Parry's rule of keeping the habit in a state of depletion, too limited and exclusive. Physiologically and therapentically the disordered nervons action, combined with disordered vascular action, ought to be taken into full account. In Howls's case, the hydrocyanic acidrin threedrop doses, combined with Bittley' solution, tartar emetic, and other nauseants, and occasionally with the fetids, to soothe the nervous symptoms, formed a very essential and prominent part of the treatment. The tartar emetic was increased to a considerable quantity before it nauseated. This combination produced the first decisive impression on the heart, and stilled it within a fortnight.

As the heart has a tendency to grow, from diseases which render it liable to congestion, so hes violent exercise, which increases the quantity of blood passing through its cavi ties, a tendency to promote that growth. This is seen in our labourers, in whom heart diseases are frequent. The increase of the arms and legs, in cases of plethoric palpitation, will throw too much blood upon the heart; but not only does muscular exercise, which returns the blood with more than usual momentum, excite excessive action on that important organ, but mental irritation, long exposure to heat, the indulgenee of the passions, the causes of fever, and various causes acting on the alimentary canal, as stimulating food, accumulations of feces, flatus, and other powers, by a mode of operation which is inexplicable, cause unusual fulness and impulse of blood upon the heart. (Dr. Parry.) Lying long in bed, thin-clad legs and feet, and brooding over the disorder, are equally hurtful. I compelled Howls to keep strict to repose and all these rules, so far as a woman's restlessness and the foolish interference of others, and their indifference to reason, would permit. It was gratifying to me to see how the heart gradually came down from violent pulsation and impulse to the natural and proper beat, and the feeling that "she had not a heart in her body." Some, says M. Andral, at the moment of coming into the hospital, present at the precordial region or elsewhire unusual beats in respect to force, brait, rhythm, \&c. But under the influerce of a rational treatment, and particularly repose, the first condition of the success of the treatmont, the signs presented by anscultation become less and less audinfe, and at last completely disappear.

$\Lambda$ s soon as I got the heart under control, I looked to the restoration of the uterine functions, which is a most important point. and always difficult to achieve. I puraued periodically the system of derivative bleeding and blisterng, and administered turyentine by the mouth and by injection. Professor Macartney remarks, that in a febrile and dry state of the body, a quantity of cold: water thrown over the body will often reproduce the suppressed secretion, and the pulse will drop twenty beats at once. The shower-hath was continued partly with this intention.

But the regular establishment of the catamenia for the first time in her life, the departure of a tenacious and habitual hysteria, at the height of maniacal excitement, the change from morbid determination to a 
regular state of the circulation, and the setin of a steady convalescence, were coincident with the action of large doses of antimony, and kept up by the combination of hydriodate of potass, digitalis, \&ce, already spoken of. In nervous, uterine, and biliary affections, I have ohtained such results from hydriodate of potass, that 1 consider it a remedy of the very first utility. After the action of this combination on Howls, and the removal of a third pericardite in $\mathrm{Mr}$. Gwymne, and of three inflammations of the chest in others, by similar powerful combinations without venesection, I have con. ceived the hope of being able to communicate such "bons moyens" as will limit, if not, in many cases, supersede, blood-letting in inflammatory states of the heart and thoracic viscera.

The shower-bath possesses a sedative power, which is a partial substitute for bleeding. The French use it as a last resource in diseases of the heart, and consider it as frequently successful after the failure of all other means. It was useful in Howls's case, and has since been beneficial to Mr. Gwynne.

The seton obviated the necessity of a great deal of Sangradoism; it was beneficial in Marshall, the case of aortic aneurysms. Dr. Jeffrey of Liverpool has given a longstanding case of palpitation, in a student, supposed to be symptomatic of organic disease, from which the patient recovered after the use of a seton.

Though I have seen with joy the subjugation of a mighty disease, after the case had been turned out as incurable from under so many stars in our particular hemisphere, I am nevertheless aware "that organic diseases of the heart generally last through life, and functional generally disappear; that the prognosis is always unfavourable; that the symptoms are generally suspended for a time, and then relapse, and terminate fatally." (Professor Home.) In organic disease nothing is more common than periodic returns. The general cause of these returns is cold, and dry cold, by contracting the circumference of the body. The blood, which permeates the capillaries under a soft temperature, flows back towards the centre, and, if an obstruction exists, it becomes relatively greater through the more energetic efforts of the principal organ of circulation. ( $M$. Rostan.) Howls at this moment (Feb. 8) has a return of slight palpitation, with impulse, pain of brain, and hysterical nervousness, and chilly extremities, from walking too far, and getting wetted through her boots in the snow. Macintosh's waterproof, and all other means that can preserve the balance of the circulation, are necessary to such people.

Ross, Herefordshire, Feb. 1836.

\section{OPENING OF THE BRACHIAL ARTERY}

IN BLOOD-LETTYNG, AND HEALING BY COMPRESSION.

Vrncent Petrel, aged forty years, a printer, was admitted at the Hotel Dieu, Paris, under the treatment of M. Sanson. He had fallen from the stair of bis residence, upon one of the last days of the month of December, by which he received contusions upon the chest, the knee, and the right foot; and also a small wound upon the integuments of the face. He entered the hospital on the 31 st of December. The pains which he experienced in the chest, particularly on movement of the intercostal muscles, the strong pulse, the injection of the capillaries of the face, and the robust constitution of the patient, showed the necessity of general blood-letting. Resolutive remedies were employed upon the contused parts, and bandages over the chest, in a serrated form, were employed, until the pains of the chest were removed. Bloodletting was performed on the lst of Janu. ary. Two prickings had been made by one of the hospital pupils in the median cephalic vein, from which only a few drops of blood were obtained. $\mathrm{He}$ pricked the median basilic vein, placed a little to the outer side of the artery, the pulsations of which were perceived. This vein was very superficial and voluminous, and much distended. Im. mediately after the puncture was made, the blood spouted out with violence over the bed, the assistants, and the operator. The jet was readily directed to the vessel intended to receive the blood. The blood was brisk (vif) and strong (fort), it was also jerking. This fluid was red, lively, and frothy.*

These characteristics of the jet of blood were sufficient, without doubt, to make known that an artery was opened, but it was needful to be assured of this. The vein was compressed below the puncture, and the jet diminished in volume, but the force was not diminished. The nature of the blood was not changed in appearance. This was put to the proof. The brachial artery was compressed between the opened portion and the beart. The jet diminished in volume, it was no longer jerking, but showed a sustained arch. Above all, its force and extent were diminished. The nature of the blood was not the same. It was dark and less frothy. In a word, it had now assumed the characteristics of venal blood. After having twice made these proofs, and obtained the same results, it was needful to act as if the artery were open. A plug

* "Frotly," from the atmospherical air which it contained as arterial blood (?)-ED. L. 